with in successive chapters by various authors. This book is therefore a useful adjunct to larger systematic texts but could not, and is not intended to, replace them.

There is a wealth of useful clinical observation confirming that clinical oncology must be based on the sound practice of medicine. The theoretical background to such problems as hypercalcaemia is done well, in almost too much detail for a book of this kind, and probably more than is required for understanding the management of the condition. The 'treatment tactics' are dealt with on sound and generally accepted lines and highlighted by short illustrative case histories. This is a very successful device for engaging the attention. Less satisfactory is the interruption of the text by aphorisms in heavy type. This makes the text disjointed and reminded the reader of the worst type of school book he was forced to read in his youth. Perhaps the publishers will persuade the Editor to get rid of them in the well deserved second edition.

\section{A Colour Atlas of Gynaecological Surgery. Vol. 4 Surgery of Vulva and Lower Genital Tract}

D. H. Lees and A. Singer. Pp. 176, illustrated. Wolfe Medical Publications, London, 1980. £25.00.

The Introduction to this volume indicates that it is in part made up of sections which might have been included in earlier volumes. Nevertheless, its layout is not quite as logical as that of its predecessors. It also contains material, some of which is not strictly relevant to its main theme of gynaecological surgery, and some of which has already been dealt with in an earlier volume.

There are useful chapters on: surgical anatomy; operations on the urethra, including urethral caruncle, prolapse of the urethra and urethral diverticulum; surgery of Bartholin's duct/gland; operations for contractions of vaginal introitus; repair of complete perineal tear, and closure of rectovaginal fistula.

The chapter on surgery of congenital malformations is almost too lavishly illustrated. For instance, there are 2 pairs of colour plates showing the appearances of the abdomen before and after drainage of a haematocolpos with haematometra; 2 colour plates of the haematocolpos in the process of draining; and one colour plate showing the bucket containing the drained material! However, the one plate illustrating the line of incision into the imperforate hymen is not at all clear. This criticism apart, there are wellillustrated sections on the surgical treatment of longitudinal vaginal septum, para-vaginal cyst, and construction of an artificial vagina. The chapter on surgery of the chronic vulva dystrophies is mainly redundant, since the operation of local vulvectomy which it contains has already been described and illustrated in great detail in volume 3 . The chapter on 'Vaginal abnormalities as sequelae of maternal diethystilboestrol treatment' also seems irrelevant, since it contains no gynaecological surgery. 'The surgical treatment of vulvar condylomata' deals in considerable detail with minor procedures such as diathermy excision and cryosurgery, as well as providing colour plates of the vulva before and after laser excisions of condylomata. There follows another entirely clinical chapter on 'Injuries to the Vulva' with illustrations of the lesions resulting from coital injuries including rape. Although this chapter contains a useful account of the way to examine such cases from a forensic point of view, its relevance in a book on gynaecological surgery is questionable.

It is perhaps consistent with the rather heterogeneous nature of this volume that it should end with a chapter on haemorrhoidectomy.

\section{Immunodiagnosis of Cancer 2}

Edited by R. B. Herberman and K. R. McIntire. Immunology Series vol. 9. Pp. xiii +576 , illustrated. Marcel Dekker, New York and Basel, 1979. Sw. fr. 123.

This book provides an extensive review of in vitro and in vivo tests used to investigate caricer patients in an attempt to provide a rationale for attempting immunotherapy in man. Compared to Part 1, which provides a useful review of immunodiagnostic tests which are being used in routine clinical practice today, little that is presented in Part 2 is of practical diagnostic value. Like the serodiagnosis of bacterial infections in the 1930s this field of study has produced an extensive literature which is well summarized in this book. As one of several recent publications covering this field. it does not stand out as offering a unique source of information, although the chapter by George Klein on the serology and cellular immunology of Epstein-Barr virus infection and its relationship to Burkitt's lymphoma and nasopharyngeal carcinoma is the most interesting contribution.

\section{Prevention in Childhood of Health Problems in Adult Life \\ Edited by Frank Falkner. Pp. 135, illustrated. World Health Organization, Geneva, 1980. Sw. fr. 18.00.}

This book should be of interest to workers in paediatrics, public health and epidemiology. It presents a review of problems in paediatrics which have long-term sequelae and influence later health. The contents include discussions pertinent to both the developed and the non-industrialized world, perinatal diseases, malnutrition, infections of the fetus and child, overnutrition, oral, and mental health. Each chapter is authored by a recognized specialist and brought together by a single editor whose extensive introduction sets the pace and scene emphasizing the need for education, awareness and understanding of how problems in childhood can affect later well-being. The text is legible, and well presented with few diagrams but useful references. The book makes interesting reading and for the Western paediatrician may open new lines of thinking. It can be thoroughly recommended.

\section{Pseudomonas aeruginosa. The Organism, Diseases it Causes} and Their Treatment

Edited by L. D. Sabath. Pp. 264, illustrated. Hans Huber, Bern, Stuttgart, Vienna, 1980. Fr. 43.00; DM 47.00.

The widespread use of broad-spectrum antibiotics and more adventurous medical and surgical procedures have led to the establishment of Pseudomonas aeruginosa as the principal hospital infection organism of the present era. It is therefore appropriate that a book should be published which deals with many aspects of this ubiquitous organism. The text is a compilation of papers which were presented at a Symposium held in Boston in 1979.

The authors, many of whom are recognized as authorities in their respective fields, provide up-to-date information on the organism, its epidemiology, and the approaches to treatment of the various infections it may cause. Particular attention is paid to infections of burns, of the respiratory tract in cystic fibrosis and to host defence mechanisms, while hospital epidemiology and control of infections in other forms of intensive care are dealt with less comprehensively.

The final section of the book comprises short selected papers on the pharmacokinetics and clinical application of cefsulodin, one of the new cephalosporins found to have appreciable activity against Pseudomonas. The results reported suggest that this antibiotic offers a real and safer alternative to existing treatments, although with the recent 